\title{
What Is Cross-cultural Research
}

\author{
ILESANMI Oluwatoyin Olatundun \\ Behavioural Studies Department, College of Management Sciences \\ Redeemer's University, Mowe, Ogun State, Nigeria \\ E-mail: toytundun@yahoo.com
}

\begin{abstract}
This paper discusses the major principles and methods of cross-cultural research, particularly how to test hypotheses on worldwide samples of cultures. The major purpose of this presentation is to encourage an increase in cross-cultural research by showing that it is not hard to do.
\end{abstract}

Keywords: Cross-cultural Research, principles, methods, hypotheses, Background, Perspectives, Subcultures, Research Process, Types, Features, Ethical Issues, \& Implications.

\section{Introduction}

Cross-cultural research is a scientific method of comparative research which focuses on systematic comparisons that compares culture to culture and explicitly aims to answer questions about the incidence, distributions, and causes of cultural variation and complex problems across a wide domain, usually worldwide. Such questions include:

- What are the patterns of coherence and sources of coherence in the practices, beliefs, social roles, norms, expressions, and forms of organization and conflict in a) human communities? b) Other forms of groups? c) Other extra-community trajectories?

- How much of that coherence is due to a) Common history, language, identity? b) Common or recurrent modes of adaptation to recurrent human problems? c) recurrent consistencies in how language, discourse and expression, social and d) Roles, norms and organizations constructed into shared cultures?

- What are the patterns of decoherence and disjuncture, misunderstanding and conflict that arise given the a) multiplicity and overlapping of cultures? and $b$ ) cleavages and disjuncture of cultures?

Cross-cultural research strives to arrive at reliably supported explanations of why things are the way they are (Hempel, 1965; Nagel, 1961) (Note 1)

To compare culture is not to deny their individual uniqueness. Cross-culturalists do not deny the uniqueness of culture; uniqueness and similarity are always present, simultaneously. Cross-cultural research deals with what is general, what is true for some or even all human cultures.

Results of Cross-cultural research are generalizable to all types of society from a small hamlet with population in the hundreds or a few thousands to urban societies with population in the hundreds of millions. It helps researchers to make general (cross-cultural) statements about the similarities and differences of cultures and to identify what may be universal and variable about human cultures, as well as to discover reasons why the variation exists (see Figure 1).

Cross-cultural psychologists generally collect primary data, they do not make use of secondary data derived from national surveys on issues such as crime rate, gross national product, etc. however, their comparison tend to be limited often only to two-cultures (the investigator's own and one other). 


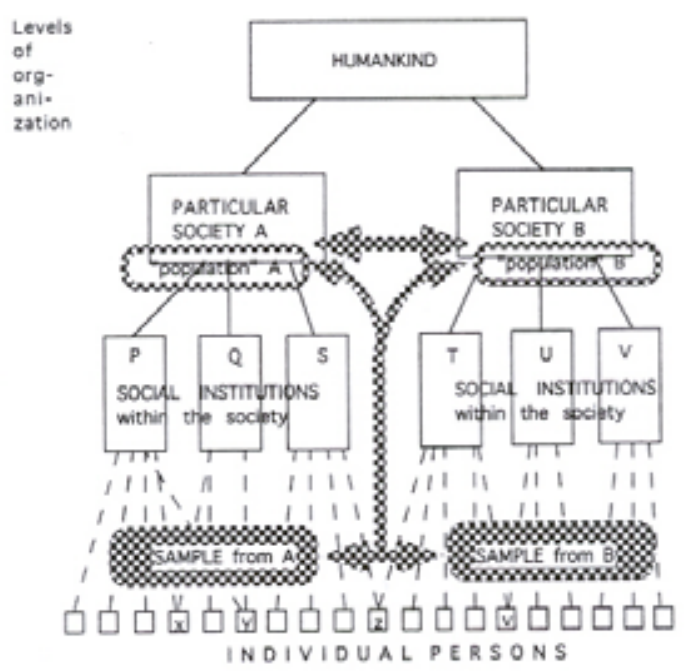

Figure 1. Creating generalized knowledge through sample-to-population inference

\section{Historical Background}

The history of cross-cultural comparison dates back to the late $19^{\text {th }}$ century when Edward B. Tylor made the move into modern cross-cultural analysis with his statistical methodology explained in school's modern premiere paper, "On a Method of Investigating the Development of Institutions, Applied to Laws of Marriage and Descent" (1889). William Graham Sumner later compiled and wrote most of the massive four-volume "The Science of Society" (1927) which was completed after Sumner's death, including the index, by A.G. Keller (Harris 1968:607).

George Peter Murdock developed the Cross Cultural Survey in the 1930s-40s at Yale, as head of the Human Relations Program. This beginning grew into the Human Relations Area Files, which is now available in over 250 institutional libraries in Africa and abroad.

George P. Murdock combined the modern statistical method with modern ethnography, and statistical cross-cultural comparative method to create the HRAF. Murdock compiled the "Ethnographic Atlas, "which was published in "Ethnology," a journal that Murdock founded in 1962. This is an atlas of the 600 societies described on the basis of several dozen coded features in Murdock's "World Ethnographic Sample."

Driver (1967) (Note 2) reanalyzed Murdock's "Ethnographic Atlas" using the two basic approaches of statistical analysis for anthropology — the cultural traits as units of analysis, as proposed by Tylor and Murdock, and the approach suggested by Boas and Kroeber, by using societies or tribes as the units of analysis. Driver combined the concepts of these two approaches and came up with a more sophisticated method by inductively determining culture areas or "sets of strata" (Seymour-Smith 1986:61).

\section{Perspectives in Cross-Cultural Psychology}

Basically, there are two types of perspectives in cross-cultural psychology: the Absolutist Approach and the Relativist Approach. The absolutists view in cross-cultural psychology is that psychological phenomena are basically the same in all cultures while the relativists view in cross-cultural psychology is that psychological phenomena should be studied only from "within" a culture where these phenomena occur.

\section{Types of Cultures: Subcultures or Populations}

Culture is a matrix of behaviours, beliefs, practices and values that typifies a particular group of people. It deals with a variety of things that influence all aspects of behaviour; emphasizes group influence rather than individual variability and essential part of the meaning-formation process.

Human communities have a variety of practices, beliefs, social roles, norms, expressions, forms of organization and conflicts (economic, political, legal, religious, expressive and artistic) that exhibit various sorts of internal coherence as well as cleavages within communities. These coherences and cleavages bear many close connections to the different historical experiences, physical and social environments in which people live. They include configurations of elements and characteristic ways of interrelating that are shared with neighbouring and interacting groups, and shared among dispersed groups that have common historical experiences and similarities, including common origin, common membership in historical civilizations, and languages that are mutually understood or that derive common families. Lines of cleavage, conflict, and marginality, of course, are part of cultural phenomena. Elements and relationships that 
individuals or communities have in common are shared in a variety of ways. Some, such as the more intensive patterns of interaction that derive from common residence, joint experience, and discourse in a common language or system of signs, are relatively well bounded. Other patterns of sharing or similarity derive from processes of dispersal: migration, Diasporas, the trajectory of lives lived through spatial movements, social mobility, careers, and distinctive histories. Interactions are by no means limited to localities, but to the trajectories of inhabitants who move through and between localities.

Cultures consist of shared constructions that emerge out of social interactions of sets of individuals who inhabit overlapping social and physical spaces. Coherence may be viewed as an emergent property, but may be present or absent to varying degrees and along varying dimensions or trajectories.

\section{Three Central Questions Revolving Around the Study of Culture}

Murdock and White (1969), in creating the Standard Sample for Cross-Cultural Research, raised three central questions that revolve around the study of culture. First, what are the foci of study? Second, what are the issues of coherence or de-coherence within the foci studied? Third, how do these issues apply between foci?

First, there is the problem of what it is that one wants to study in terms of foci: in their case, Murdock and White (1969: 331) take up the issue of sampling the diversity of human communities in order to learn something about coherence or decoherence within and between communities. Comparing communities (through ethnographies) is not the only approach to cultural comparisons, but it is the one that focuses on clusters of people who inhabit, at least in part, specific and stable community sites which are often the loci of ethnography. Other standard samples could be those devoted to the study of: migration; institutions and organizations; particular types of cultures; subcultures or populations. Their insistence on this point is not on communities as representatives of larger cultures, but on communities at pinpointed times and places in which ethnographic study has been sufficiently well carried out. That is, it is possible to list, from the ethnography, what specific bundles of practices, beliefs, social roles, norms, expressions, forms of organization and conflicts (economic, political, legal, religious, expressive and artistic) are present in each of the specific times and places of the distinct ethnographic foci that constitute the sample.

Second, there are the problems and issues of coherence or de-coherence within the foci studied, as in the comparative study of human communities. The functionalist approach to ethnography was vastly over generalized in its heyday, which lasted from the 1920s through the 1970s. Murdock and White (1969:329-330) emphasize the weakness of the functionalist arguments that were commonly used by ethnographers to argue for the cultural coherence of the communities they studied. Functional linkage of traits asserted by an ethnographer in one society, for example, are often contradicted that one trait but not the other is present in a similar neighboring society, or by the fact that the traits do not correlate across societies.

Third, there is the problem and the issues of coherence or de-coherence between foci in the study of human communities due to common historical origin or experience. Murdock and White (1969:330) note that the conjectures of those anthropologists who attempt to reconstruct culture history on the basis of trait similarities are not notably superior to those of ethnographers who investigate functional relationships.

\section{The Cross-Cultural Research Process}

The research process in cross-cultural study is circular in nature (as indicated in Figure 2 above), with built-in evaluation mechanisms at each stage of the process, which may cause the researcher(s) to re-evaluate decisions made at previous stages. McGrath (1982, p. 71) stated that cross-cultural research should be viewed as a series of "logically ordered - though chronologically chaotic - choices" about potential cultural ki's. 


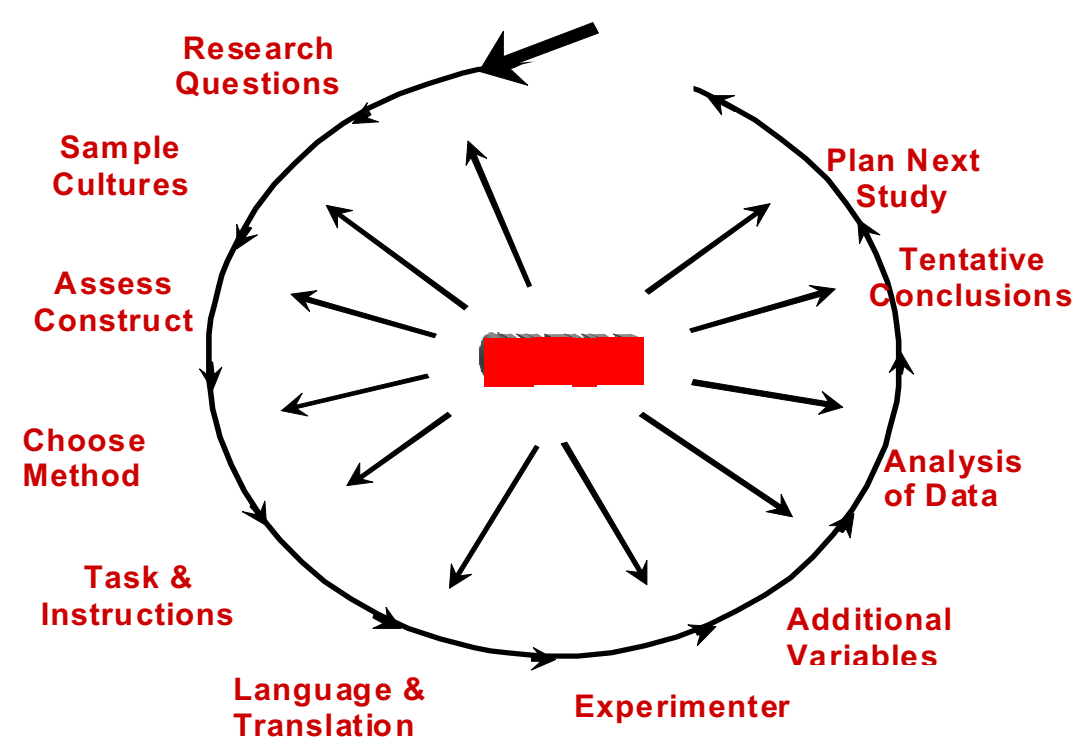

Figure 2. cross-cultural research process

\section{Types of Cross-cultural Research}

There are several types of cross-cultural research. The first of which is Regional comparative cross-cultural research which is well represented by the works of Kroeber and Driver. This approach is an attempt to define classifications of cultures and to then make inferences about processes of diffusion within a cultural region (Levinson and Ember 1996:263). Regional comparativists are likely to know a lot about each society in a within-region comparison but may not know all the cases in the region that depends mostly on the size of the region (Burton \& White, 1991).

Next is small-scale regional comparison advocated by Fred Eggan (1954) (Note 3) who called it "controlled comparisons" on the assumption that it may make it easier to rule out possible effects of similarity in history, geography, and language. His assumption was that researchers could readily discern what accounts for some aspect of cultural variation within the region if history, geography and language were held constant. This is the approach toward smaller scale comparative studies. Eggan suggests the combination of the anthropological concepts of ethnology with structure and function, allowing the researcher to pose more specific questions on a broader range of subjects (1961, 125-127) (Note 4). An example of this type of study is Spoehr's study which examined the changes in kinship systems among the Creek, Chickasaw, and Chocktaw, and other regional tribes of the Southeast after their removal to the Oklahoma reservations. Spoehr detailed these changes with an analysis of the historical factors responsible for them and the resulting processes (Eggan 1961, 125-126) (Note 5).

Another type is large-scale within-region research (using data on all or most of the cultural traits in the region) which generally tries to arrive at classifications of cultures in order to make inferences about processes of diffusion and historical ancestry (Burton \& White, 1991). within-region comparativists are interested in trying to see how the cultures in the region are related to each other (Jorgensen., 1974) (Note 6).

Holocultural analysis or worldwide cross-cultural analysis which developed out of the ancestry from Tylor to Sumner and Keller, and then to Murdock is another type of cross-cultural research. According to Levinson (1977:3) (Note 7) holocultural study "is usually designed to test or develop a proposition through the statistical analysis of data on a sample of ten or more non-literate societies from three or more geographical regions of the world". In this approach, cultural traits are taken out of the context of the whole culture and are compared with cultural traits in widely diverse cultures to determine patterns of regularities and differences within the broad base of the study. These approaches differ on the determination of what constitutes a unit of analysis.

Another type is coding which implies that data can be collected in two ways. First, data can be coded directly from ethnographic sources, or from ethnographic reports in the HRAF files. Second, is the usage of previously coded data from coded ethnographic sources or previous holocultural studies. Levinson and Malone suggest coding the dependent variables from HRAF files or ethnographic sources, and collecting independent variables from compendia of coded data.

Inferential studies are another type of cross-cultural research. These are used to answer important or challenging questions such as "so what?" or "What does it mean?" 
The last is emic vs. etic models. Emic models view behaviour as culture-specific phenomenon which must be understood in the context of a particular culture while etic models view behaviour as universal phenomenon which must be understood in comparison to behaviour in other cultures. Thus, three approaches (or combinations thereof) are possible: Subjective single-culture, Objective single-culture and Objective cross-cultural.

\section{Advantages and Disadvantages of Different Types of Comparison}

Worldwide Cross-cultural comparison has two major advantages (Ember, 1991) (Note 8). First, the statistical conclusions drawn from a worldwide comparison of all type of society are probably applicable to the entire ethnographic record, assuming that the sample is more or less free of bias. That is to most if not all regions and all types of societies in the ethnographic record. Thus other thing being equal, the worldwide type of cross-cultural comparison has a better chance than other types of comparison of coming close to the goal of knowing that a finding or an observed relationship has nearly universal validity, which is consistent with the general scientific goal of more and more comprehensive explanation.

Next, worldwide cross-cultural research maximizes the amount or range of variation in the variable investigated thereby making a difference between a useful and a useless study. Without variation, it is impossible to see a relationship between variables. If for instance a researcher uses data from a single society; a single region, or even from the recent historical record for nation-states, there may be little or no variation to relate to other things. Even if there is some variation, it may be at just one end of the spectrum of variation. Hence, one may assume that a relationship is positive or negative, because that is all one observe in the region or in one type of society, but the relationship may be curvilinear in the world (Whiting, 1954:524-25). Hence, a worldwide cross-cultural comparison is needed to be sure about the nature or shape of a relationship. A worldwide cross-cultural sample represents the maximum range of variation in the ethnographic record. It is the most reliable way to discover exactly how variables are related in the entire range of human societies.

Besides these major advantages, a worldwide cross-cultural study might be unsuccessful and the researcher could get stuck. A researcher is unlikely to know much about individual societies when comparing a lot of societies from different parts of the world. If a tested explanation turns out to be supported, the lack of detailed knowledge about the sample cases is not much of a problem. If, however the cross-cultural test is disconfirming, it may be difficult to come up with an alternative explanation without knowing more about the particular cases. More familiarity with the cases may help in formulating a revised or new theory that could be tested and supported (Johnson, 1991)(Note 9).

\section{Methodological Concepts in Cross Cultural Research}

There are primarily two main methodological concepts in cross-cultural research. The first is that comparison is essential to anthropological research. Therefore to understand culture, societies must be compared. The comparative method is a search for comparable cultural patterns in multiple societies, particularly the comparison of cultural traits taken out of cultural context (Winthrop 1991: 43).

Secondly, all theories, despite fads or current trends require testing. Without comparison there is no way to evaluate if presumed cause and effect are related. This relates to the logical "if" ---"then" inductive process. If cause is not present then the effect should not be present (Levinson and Ember 1996:262). Cross-cultural analyses are used to describe the range and distribution of cultural variation existent in the ethnographies recorded as well as to test the hypotheses and theories that are proposed to explain the variation recorded (Levinson and Ember 1996: 261).

\section{Methods of Observation in Cross Cultural Research and, Their Significance}

Cross-cultural researchers usually employ standard principles of scientific method and research design-random sampling techniques which are supposed to be unbiased, reliable or repeatable measurements so that others can try to replicate their results and the researchers may determine how much confidence they can place in such results. These methods are case-study, survey, testing method, naturalistic-observation, laboratory-observation, correlational method, and experimental method

The case-study method is a carefully drawn biography that may be obtained through interviews, questionnaires, and psychological tests. The survey method is a method of scientific investigation in which a large sample of people is questioned about their attitudes or behaviour. There are three types of survey research design. These are direct surveys, indirect surveys and focus group method. With direct surveys Interviewer maintains or can maintain a direct communication with the respondent and is able to provide feedback, repeat a question, or ask for additional information. Through indirect surveys, researcher's personal impact is very small because there is no direct communication between the respondent and the interviewer. The questions are typically written and handed in, mailed, or sent electronically to the respondents' homes, classrooms, or work places. The focus group methodology is a survey method used in academic \& marketing research. The most common usage is one where a group responds to specific social, political, or marketing messages. The typical focus group contains $7-10$ members who are experts, potential buyers, viewers or other customers. 
The testing method entails the usage of psychological tests like intelligence, aptitude, and personality, to measure various traits and characteristics among a population by psychologists. Such testing instruments must be standardized, show face and concurrent validity, and reliability. They must have established norms as well.

The naturalistic-observation is a scientific method in which organisms are observed in their natural environments while the laboratory-observation is a method where a place is found in which theories, techniques, and methods are tested and demonstrated.

The correlational method is a scientific method that studies the relationships between cross-cultural variables. The Correlation coefficient is a number between +1.00 to -1.00 that expresses the strength and direction of the relationship between two variables. There are two major types of correlation: Positive correlation (which implies that increases in one variable are associated with increases in the other; decreases are likewise associated) and Negative correlation (which implies that increases in one variable are associated with decreases in the other) (see Figure 3).
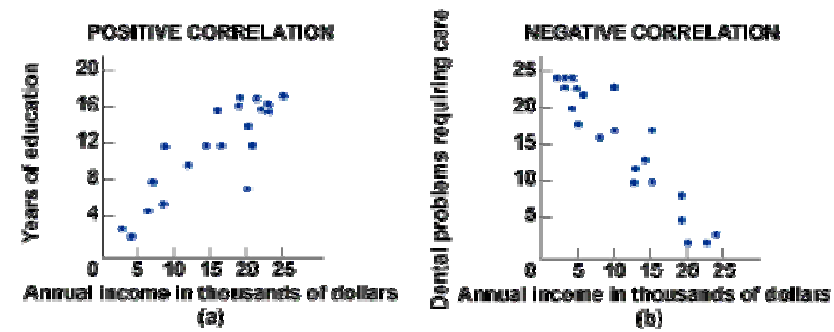

Figure 3.

The experimental method is used to hunt for causes of cultural variations in societies. The experimental variables consist of the independent variable which is a variable that an experimenter manipulates and the dependent variable which is a variable that an experimenter predicts will be affected by manipulations of the independent variable (see Figure 4). The experimental design has three elements: Treatment, Experimental subject and Control subjects. The treatment refers to a condition (which may be placebo, blind or doubleblind) received by participants so that its effects may be observed. Experimental subjects receive the treatment and the Control subjects do not receive the treatment but for whom all other conditions are comparable to those of experimental subjects.

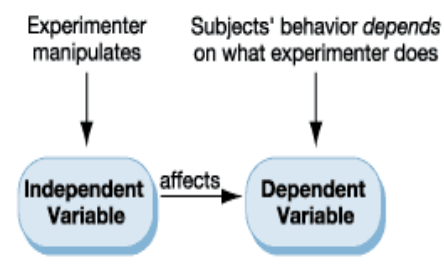

Figure 4.

All cross-cultural research methods may be employed in either Cross-Sectional Study or Longitudinal Study. Cross-sectional study is used to compare subjects of different ages at a given time but in longitudinal Study subjects are followed and periodically reassessed over a long period of time (see Figure 5).

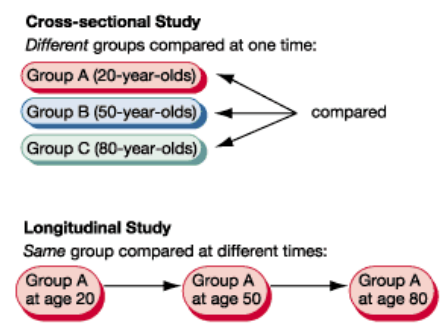

Figure 5. 


\section{Features of Cross-cultural Research}

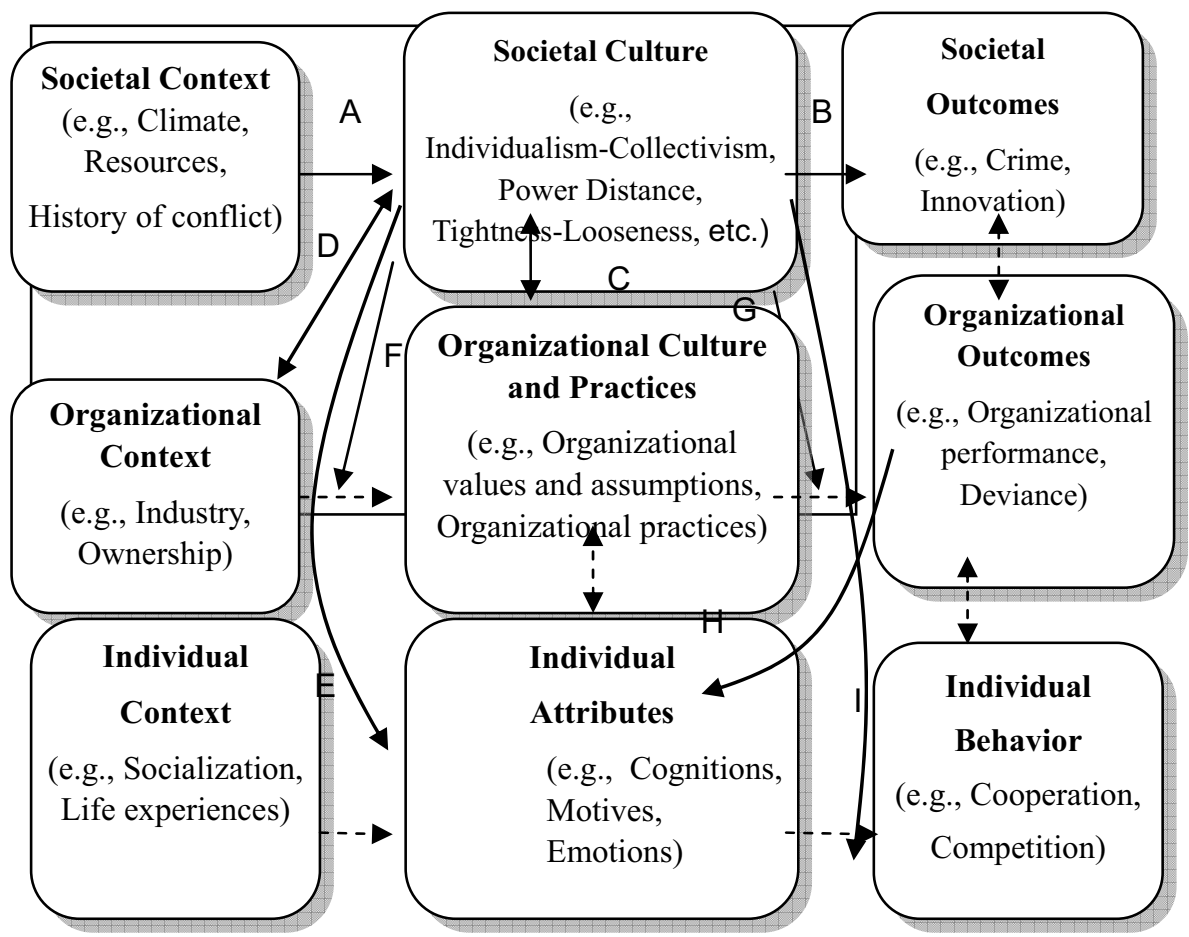

Figure 6. A typology of cross-cultural research questions

Essential features of cross-cultural research are question, sampling, theories and hypotheses, operational definition, and principle of falsifiability. The research question has to be a clear, one sentence practical question which can be answered in a reasonable time frame (Figure 7 below presents a typology of cross-cultural research questions)

Cross-cultural (worldwide comparative) researchers usually ask four kinds of questions. These are descriptive question, causal question, consequence question and non-directional relational question. Descriptive question usually deals with the prevalence or frequency of a trait. Examples are: how common is the belief that sex is dangerous to one's health? How common is it for a society to allow polygyny? Are peaceful societies common? Is the custom of marriage universal? What percentage of the world's societies practice polygyny? Which is the most important subsistence activity among food collectors - gathering, hunting, or fishing? How common is female infanticide?

Causal question seeks answers about the causes of a trait or custom. Examples of causal questions are: Why is polygyny permitted in most societies known to anthropology? Why do women (as opposed to men) do most of the agricultural work in some societies? Why is the extended family the customary form of household in many societies?

Consequence question asks about effects of the consequences or effects of a particular trait or custom. Examples of consequence questions are: What are the effects on infant care of high involvement of women in subsistence activities? Does punitive child training affect the frequency of warfare?

Non-directional relational question asks whether two traits are related or not, without implying cause or consequence. Rather than postulating causes or consequences, a researcher may simply ask how a particular aspect of culture may be associated with some other aspect(s). For example: Is there an association between most important subsistence activity and level of political complexity?

Causal question and Non-directional question are relational questions that ask how traits are related to other traits. Of the four types of questions, the causal of 'why' question is the most challenging because it rarely specify what the researcher needs to do to answer the question. The descriptive question tells the researcher what to count. The consequence question can also be unspecific or open ended; the possible outcomes may not be specified in advance. 


\section{Figure 7: Types of Relational Questions}

\section{Causal Question:}

Independent variable dependent variable

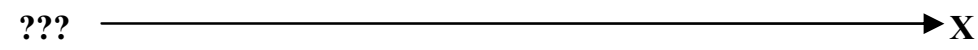

\section{Consequences Questions:}

Independent variable

dependent variable

$\mathbf{X}$

Independent variable

dependent variable

$\mathbf{X}$

Non-Directional Relational Question:

variable1

variable2

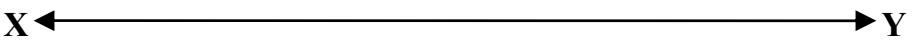

The "consequence" and "relational" questions usually specify two sets of concrete phenomena that may be related to look at. If you want to know whether type of marriage has an effect on or is related to fertility, then there is the need to measure both variables (types of marriage and fertility). But the causal question does not tell the researcher where to look for causes. It only specifies what scientists call the dependent variable (the thing to be explained).

With regards to sampling, cross-cultural researchers must decide what societies to examine because no one can examine all cultures. The most important operating principles in a scientific test of hypothesis are: 1) to choose a sample that is representative of some universe of societies the researcher wants to generalize the results to; and 2) to use a large enough sample such that the results are likely to be true for the larger universe of cases.

Theories and Hypotheses are ideas (implicit or explicit about how and why things are the way they are) underlying descriptive, consequences, causal or non-directional relational questions. Spelling out the assumptions and reasons for a researcher's expectations can clarify his theorizing and also help derive hypotheses that could be tested. Theories are assumption of laws and statistical associations which do result in predictions called hypotheses. For instance:

Assumption 1: Males will be more aggressive than females

Assumption 2: Individuals with higher levels of androgen will be more aggressive.

Cross-cultural analysts test hypotheses and draw statistical correlations based on the assumption of the existence of universal patterns (Naroll 1961, 221).

Operational definition is a precise definition of a term in a hypothesis, which specifies the operations for observing and measuring the process or phenomenon being measured. The principle of falsifiability assumes that a scientific theory must make predictions that are specific enough to expose the theory to the possibility of disconfirmation; that is, the theory must predict not only what will happen, but also what will not happen.

Other features include participants, replication (The ability to repeat, reproduce or copy a study), selection factor (The bias source that may occur when subjects are allowed to determine for themselves whether or not they will receive a treatment condition in a scientific study), and measures for each variable in the hypothesis. Devising a measure involves at least four steps; 1) theoretically defining the variable of interest (in words or mathematically); 2) operationally defining the variable, which means spelling out the "scale" that the researcher has devised for measuring it; 3) telling the coder where to find the required information and 4) pre-testing the measure to see if it can be applied generally to 
most cases. Designing a measure requires some trial-and-error. If the scale is too confusing or too hard to apply (because the required information is lacking), the measure needs to be rethought. For instance, the degree to which a society has extended family households needs to be defined. The researcher needs to state what an extended family means, what a household means, and how he will decide the "degree" to which a sample society has extended family households. Having defined the concepts, the researcher must specify how to measure the degree to which a society has extended family households.

Next is analysis of results which is used to determine if the predicted relationship actually exists in the data. It is precisely here that cross-cultural researchers usually resort to statistical tests of significance. There are several Statistical tests that show how "perfect" a result has to be for us to believe that there is probably an association between the variables of interest, that one variable generally predicts the other. Essentially, every statistical result is evaluated in the same objective way. The question is asked: What is the chance that this result is purely accidental, that there is really no association at all between the two variables. The answer always involves a probability value (or $p$-value), the likelihood that the observed result or a stronger one could have occurred by chance. So, if a result has a $p$-value of less than .01 , this indicates that there is less than one chance in one hundred that the relationship observed is purely accidental. A p-value of less than .01 is a fairly low probability; most social scientists conventionally agree to call any result with a $p$-value of .05 or less (five or fewer chances in one hundred) a statistically significant or probably true result.

\section{Changing Face of Cross-cultural Research}

This focuses on the recent advances in cross-cultural research. The first of which is Kurt Lewin's new conceptual and methodological strategy for cross-cultural research based on field theory. This has been applied to several recent research projects and has shown to be capable of explaining seemingly paradoxical findings. It focuses on issues such as: (a) the place of objective, social, and subjective realities in such research; (b) the importance of considering the relationship between these realities; (c) the role of an interdisciplinary perspective; and (d) the appropriateness of traditional research methods.

Next are the current developments in the collection of survey data via the internet, including both the methodological strengths and weaknesses of this approach, as well as current standards for best practice. A range of benefits are claimed for online research: lower costs; faster turnaround; higher response rates; lower refusal rates; lower respondent error; broader stimuli potential; flexibility in the form of adaptive questioning; and even greater enjoyment (Smee, Brennan, Hoek and Macpherson 1998; Forrest 1999; and Kehoe \& Pitkow 1996). The methods often used involve email surveys, postal invitations to visit a website and complete a web form, and email invitations to complete an online survey or web form.

Three dimensions already suggested as appropriate for analyzing data collection methods are validity, reliability and practicality (Weible and Wallace 1998). 'Practicality' is seen as 'efficiency' and "concerns the complexity of the data collection process, and includes cost, ease of administration, and the ease of analyzing and interpreting data" (Weible and Wallace 1998). A review of the academic literature illustrates that analyses of the practicality of using online data collection methods have mainly involved non-probability samples and that there are a number of issues which are significant from the viewpoint of maintaining data integrity while trying to gain greater efficiency. These issues are particularly significant in the area of cross-cultural research.

With electronic surveys, there are a number of technical issues to be overcome. The first of which has to do with sampling. Sampling is perhaps one of the greatest threats to online surveys. This may be tied to the impact of individual's response to electronic equivalent of junk mail and therefore on sampling error. It is instructive to note that SPAM is technically the use of a Newsgroup or mailing list to send unwanted email. An issue is where the respondent's email address came from as far as the authors are concerned. However, from trials to date using email addresses of information technologists and judging their responses, many define SPAM as simply any email received from anyone they do not know. It is felt that the same situation may hold true for 'cookies' and their intrusive use. This is turn may bias the sample and also account for slowing response rates and increasing refusal rates

Another issue which undoubtedly impacts on the representativeness of online samples is the matter of bad email addresses. Comley (1996) reported a study comparing data collection using email $(1,221$ sample), post $(1,769)$ and a postal invitation to complete a web based form $(1,000)$ that bad email addresses were high at $35 \%$. While immediate notification of bad email addresses is an example of the flexibility of online data collection methods there are significant issues involved. The sample in the Comley (1996) came from a less than one year-old database of UK Internet users who read an online magazine. This suggests that email addresses may change more often than might otherwise be suspected. Another issue concerns whether or not the receiving mail server is barring the mail because it is regarded as SPAM. Comely (1996) also illustrates that while it is difficult to measure response quality, the dimensions item omission, response error and completeness of answer are guides. 
It is suggested that care is needed in ensuring that input translates into output fields as intended and in particular, care is needed with the number and type of characters permitted in open-ended questions using textboxes in web based forms. For example, an unwanted RETURN character in a textbox may signal to SPSS or another software package that a new response starts at this point. There are other technical issues such as high screen resolution dependency, Java script, 'cookies' and adaptive questioning when browser technology and computer hardware and firmware is not yet uniform enough to permit such technological enhancements and assumptions. The issue of duplicate responses can arise in many online consumer or end-user surveys. To avoid this, researchers need to input a unique server-generated password for each respondent. This approach will avoid over-sampling in that only a single response is accepted to the Oracle database for each respondent, thus also overcoming another issue: that of pressing the SUBMIT button more than once.

\section{Problems Encountered in Cross Cultural Research}

Although cross-cultural psychology has advanced our understanding of cultural aspects of psychology, it is marred by theoretical and methodological flaws. These flaws include misunderstanding cultural issues and the manner in which they bear on psychology; obscuring the relation between biology, culture, and psychology; inadequately defining and measuring cultural factors and psychological phenomena; erroneously analyzing data and drawing faulty conclusions about the cultural character of psychology.

Another problem involves difficulties in obtaining a representative sample. Factors influencing representative samples are subject availability, willingness to participate, geographic isolation, and unavailability.

A third problem has to do with measurement which may lead to imposed etic (Berry, 1969) which is the imposition of the behavioral definition and measurement techniques of the researcher's home culture on the subjects in the research field. For instance, there are differences between African and Western model of thought. The Western thought may not transfer easily to another culture thereby leading to an imposed etic (Berry, 1969). Hence, this fundamental thinking difference and cultural belief system has important effects on ethnographic research methodologies and results. When employing Western methods, it cannot be assumed that the Africans will respond the same way as Western respondents do.

Another serious issue is equivalence (bias). In behavioral definition and research instruments (Lonner, 1979) equivalence (bias) has to do with the similarity in conceptual meaning and empirical method between cultures. If any of these aspects are not equivalent across cultures then comparison is not valid. There are functional equivalence (whether behavioral phenomenon serves the same purpose or intent), conceptual equivalence (meanings associated with similar stimulus across different cultures), metric equivalence (assumes numeric scales measure a concept equally) (Problem e.g., I.Q.) and linguistic/translation equivalence (which entails researchers understanding of subject's response and respondents their understanding of researcher's questions, culturally idiographic terms- words or terms unique to the culture and culturally isomorphic terms- words or terms in both cultures with different meanings E.g., out-of-sight, out-of-mind; view/intellect).

Possible solutions to problems raised above will require the use of back translation and an emic approach when conducting cross-cultural research. Back translation implies the use of translators capable of communicating in both languages fluently as well as interpreting conceptual, cultural differences and domain knowledge. An often overlooked factor in cross-cultural research is the assumption that hiring local translators shuttling information between two different cultures will yield the same research results. It is important to note that domain and cultural knowledge of the translator and his/her understanding of the relevance of the research results applied to design are critical for accurately interpreting conceptual differences. Purely translating between languages word for word will guarantee mis-representation of information as well as skew research findings. An example of this is shown on figure 8 below where the phrase "Designed for Use" in English is translated to "Easy to Use Design" in Chinese.

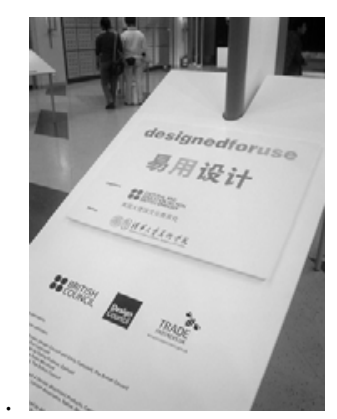

Figure 8. Language Translation versus Conceptual Translation 
Cross-cultural researchers need to use an etic-emic approach with observation and collaboration from members of the other group in assessing their constructs of interest. This will demand researchers starting from a particular cultural perspective (etic), gathering emic information from other countries (e.g., interviews, focus groups), incorporating this information and deriving a new etic so that the final construct is appropriate and representative of all cultures.

\section{Ethical Issues in Cross Cultural Research}

Ethical Issues in cross-cultural research involve issues such as values and worldviews, definitions, research design, informed consent, entry into the field, confidentiality, approaches to data collection, participant roles, ownership of data, writing, representation, and dissemination of results.

With respect to values and worldview, Hudson \& Taylor Henley, (2001); Sue \& Sue, (1990) noted that marginalized and minority participants frequently report feeling misunderstood by researchers from mainstream (Euro-American) culture. Rapport building can be used by the researcher to foster relationships with minority participants (Stubben, 2001; LaFromboise, 1993; Westwood \& Ishiyama, 1990). A key to understanding and conducting research with participants from cultural minorities is the utilization of a systems approach (Sue \& Sue, 1990). For example, Aboriginal families tend to include extended family members, place importance on collective identity and strong tribal affiliations (Thomason, 1999). Pedersen (1991) suggests that no two families, or groups, are ever culturally the same; each family internalizes aspects of the cultural norms of the group in its own way. Factors such as acculturation, class, education, and ethnic identity underpin such within and between group differences (Axelson, 1990). Religion and spirituality are often extremely important factors in the lives of ethnic minority clients, and can provide a valuable source of social connection and self-esteem in times of stress or crisis (Malone, 2000).

Kerwin and Ponterotto (1995) describe "bicultural families," in which the parents come from two different cultures (often one from the dominant culture and one from a minority culture). Healthy identity development for young people from these bicultural families involves integrating both cultural backgrounds into one self-concept that is unique (Diller, 1999). For example, today's North American Asian and Aboriginal youth often possess a bicultural identify in which they identify with both traditional beliefs and self-awareness as well as contemporary or more European-North American values; this bicultural sense of self is usually linked to level of acculturation (Herring, 1999; Wetsit, 1999; Ho, 1994).

External factors such as racism and prejudice, economic status, and level of acculturation (Diller, 1999) are often interrelated in psychosocial development in a culturally pluralistic society (Koss-Chioino \& Vargas, 1992). For example, traditional Native youth are raised within the context of the extended family (grandparents, aunts, uncles, cousins, etc.), all of whom hold responsibility for the socialization process (Herring, 1989; Wetsit, 1999). Therefore, understanding the culture's concept of family is a necessity for effective cross-cultural interactions, including the research relationship (Koss-Chioino \& Vargas, 1992). Developmental tasks can also be impeded by language barriers, poverty, and stereotypes, which limit both perceived and real access to available resources (Rivers \& Morrow, 1995).

Herring (1999) and Atkinson, Morten \& Sue (1993) also suggest that socioeconomic concerns, societal discrimination and poverty are some of the issues faced by many people from ethic/cultural minorities. The impact of underemployed and unemployed parents on marginalized youth is tremendous; it has been suggested that the most immediate effect of poverty is restricted access to environmental resources with which to improve lack of health care services and education, substandard housing, and inadequate nutrition (Rivers \& Morrow, 1995).

These above factors related to cultural context and social environmental issues are salient issues in psychosocial development, and can significantly impact the mastery of key developmental tasks in childhood and adolescence (Pedersen, 1991). Research investigations must, therefore, be based on an understanding of diverse cultural dynamics and their necessary impact on psychosocial development.

Research design is another ethical issue in cross-cultural study. It focuses on the incongruence which may exist between researchers' views or theoretical frameworks and those of the group or culture in any research project. Where differences exist between researcher and participant, they must be respected, and care must be exercised to not project one's own values onto the research process, nor judge a participant's behaviour that varies from one's own culturally sanctioned standards (Lee, 1995). For example, mental health professionals and researchers have tended to adopt Western European, largely male cultural definitions of what constitutes healthy and normal functioning (Thomason, 1999). Self-reliance, self-actualization, assertiveness, autonomy, in sight, and resistance to stress are seen as some of the tenets of healthy mental functioning (Sue \& Sue, 1990). These are the goals toward which clients are often encouraged to strive; these qualities are not, however, valued equally in all cultures. For example, effective healing for First Nations means working on interconnectedness rather than autonomy, which is often the goal for individual focused therapy (Appleton \& Dykeman, 1996). Therefore when considering research procedures or instruments across cultures, it is important to take varied meanings into account (Peavy, 1998). 
Educational attainment and achievement is another area that is greatly impacted by cultural definitions and expectations for success in life and work. For instance, some collectively oriented cultures view individual educational and vocational achievement as important only when it positively impacts the group, in contrast to a typical Euro-North American emphasis on individual growth and goal attainment (Atkinson, Morten, \& Sue, 1993). When working with participants in a cross-cultural situation, researchers must be aware of differences related to local norms, mainstream culture knowledge, language proficiency skills, educational opportunities, and culturally appropriate role models (Daily, 1988; LaFromboise, 1993; Martin \& Farris, 1994). Additionally, minority and marginalized groups face limited access to educational and employment opportunities (Diller, 1999). Research interpretation and recommendations can thus be impacted by factors such access to educational and employment opportunities, or socioeconomic status (Herring, 1999).

In terms of informed consent, cross cultural research and interaction requires a special definition (Piquemal, 2001). In some cultures, ethics is a more fluid concept that requires constant reexamination and redefinition; therefore informed consent must be viewed and implemented as an on-going process. That is consent must be asked for and given at almost every step of the research process to assure that it is valid and that the participants remain fully informed and cognizant of each aspect of the research proceedings. The standard letter of consent that participants read and sign is only one part of this process, and indeed, can act as a barrier to truly informed participation unless fully explained in understandable language.

The source of consent for many marginalized groups also requires special consideration and so must be more clearly and operationally defined. This must be done on a case-by-case basis because each ethnic/cultural community or group has a strong and self-created identity that is each unique and different from other cultures' notions of self-identity. Identity, as community research itself, must be viewed through a process of interpretation which focuses more on the importance of the relationship and experience itself rather than its content (Piquemal, 2001).

Entry into the field in research across cultures requires researchers to proceed in culturally sensitive ways. Respect and continuous communication are two essential elements in this process (Mtonga, 1986). Asking, rather than telling, and an on-going consultation with knowledgeable key informants in the community will help to build mutually beneficial research partnerships.

Community control involves the participation of community members to define and flesh out their social realities, and to decide who and what is researched in their communities. This type of participation, in the context of a research project, serves to increase a group's autonomy through the process of praxis (Hudson \& Taylor-Henley, 2001). The notion of control demands that research processes empower the community by respecting cultural values and belief systems, which traces back to a basis of ensuring informed consent. Integral to a community's control over research is authority over a project's agenda (its purpose and methodology), budget, and participant selection (Hart, 1995). For example, in a cross-cultural context, the host community and not the researchers must themselves select consultants throughout the research process, demonstrating a clear link between concepts of informed consent and control in the research design and implementation. However, Hudson and Taylor-Henley (2001) caution that control is something that must be measured by degrees and that it is unrealistic to believe that a community can have complete control over a research project implemented by outsiders. Instead, the relationship should be viewed as a partnership agreement, but with major decisions ultimately made by the community. A closer look at the theme of control suggests that if there is social or political dissent or problems within a group or community, deciding which members should be legitimate spokespersons or co-researchers might be difficult. Kerr (2002) states that adherence to research procedures such as random assignment and unbiased participant selection within the community can be one way to deal with such issues.

On the area of approaches to data collection, issues such as community damage and inaccurate findings have been identified as major concerns with ethic/racial minority participants (Ponterotto \& Casas, 1991). Culturally appropriate research affords a method that allows socially legitimate collective knowledge to be used as part of the methodological framework of the research (Brandt-Castellano, 1986). To Parlee (1983), "Psychological knowledge would be dramatically changed if it were consistently developed through interaction with its 'subjects' and its intended audiences instead of being developed with professional colleagues in mind and 'given away"' (p. 1).

Participants' role in cross-cultural research is expected to be participatory. Participatory action research (PAR) (Sommer, 1999; Hoare, Levy, and Robinson (1993) is an approach that relies on community member participation to examine social reality and the creation of local skill capacity for the express purpose of creating community autonomy through the process of praxis. PAR is mostly advocated as an effective research methodology for working with marginalized populations, including the poor, women, and immigrant (Choney, Berryhill-Paapke, \& Robbins, 1995). It is value-driven instead of value-neutral, and has several related objectives: to improve the lives of the participants; to advance knowledge; and to improve the practice of AR through a critical examination of the collaborative process (Hart, 1995).

With writing, representation, and dissemination of results, Herring (1999) noted that some cultural groups have been made suspicious of outside research because of historical exploitation that did not accurately express their cultural 
experience and did not benefit the community in any way. Several reasons for community damage from research/ psychological practice have been identified. One is that much research is done from a dominant culture perspective that is either derogatory or a romanticization of marginalized identity and life-style (Weenie, 2000). In addition, researchers have tended to generalize a specific culture when concentrating on specific cultural problems (Smith \& Morrissett, 2001). Also, generalized research results or "truths" are often culturally inaccurate (Smith \& Morrisette, 2001). Researchers need to work with community members to help ensure appropriate and representative portrayals in their dissemination.

Another issue is community ethics which deals with concerns about power centre around who makes decisions about research processes, methodology, data collection and analysis. In a research relationship, community ethics is a concept that means that a collaborative and agreed-upon decision-making process exists that enables communities to hold the power the research (Hart, 1995). However, in terms of research ethics, the community may not always have the information or knowledge to make sound ethical decisions which the academic researcher is, at least, ethically bound to consider. For instance, in a community-based research project, the co-researchers from a community may formulate questions for a survey that the academic research questioned ethically, but the researcher may respect the community-researchers' power in the process.

\section{Implications of Ethical Issues on Current Priorities and Future Directions in Cross-Cultural Relationship}

Understanding the impact that cultural influences have on basic values, priorities, beliefs, and behaviours is of critical importance. Academic researchers must recognize the likelihood for differences in perceptions when working with participants from diverse cultural backgrounds. Respect and acknowledgement of community values, differing worldviews, and ethical practice are salient issues for cross-cultural researchers. Taking the necessary time to get to know and understand community workings is critical also. Researchers must recognize that almost all marginalized and minority groups have shared certain undesirable experiences in common such as prejudice and stereotyping, socioeconomic and career disadvantages; and struggling to maintain their own ethnic identity while adapting to life in the dominant culture. Collaboration and consensus, communication, and negotiating partnerships are necessary considerations for researchers entering cross-cultural situations. Participatory Action Research (PAR) methods are particularly appropriate in these contexts.

\section{Conclusion}

A culture comprises an amalgam of shared values, meaning and interpretations of behaviors. This cannot be adequately understood simply by studying samples of individuals. Researchers need to develop a conceptual framework that will enable them to classify how samples differ. However, that framework must be constructed on the basis of concepts that are not simply derived from one culture and imposed on others. Thus researchers' culture-level concepts must arise from parallel individual-level analyses. Once there is a valid culture-level concept, researchers can use it to interpret differences in culture-level phenomena. However, if researchers wish to interpret individual-level differences within two or more cultures, then they need to draw on measures of cultural orientation that are also available from the individuals whom they are studying. In this way studies can be made which can test for universal effects and also explain why those effects are sometimes reduced or even reversed in some locations.

\section{References}

Argyris, C., Putnam, R. \& Smith, D. M. (1985). Action science. San Francisco, CA: Jossey-Bass

Atkinson, D. R., Morten, G., \& Sue, D. W. (1993). Counselling American minorities: A cross-cultural Perspective, 4th ed. (pp. 123-144). Madison, Wisconsin: Brown \& Benchmark.

Berry, J. W. (1969). On cross-cultural comparability. International Journal of Psychology, 4, 119-128.

Brandt-Castellano, M. (1986). Collective wisdom: Participatory research and Canada's Native people. The IDRC reports, 15, 3, 24-25.

Burton, Michael L. \& White, Douglas R. (1991). Regional Comparisons, Replications, and Historical Network Analysis. Cross-Cultural Research, Vol. 25, No. 1-4, 55-78. DOI: 10.1177/106939719102500104

Choney, S. K., Berryhill-Paapke, E., \& Robbins, R. R. (1995). The acculturation of American Indians: Developing frameworks for research and practice. In J. G. Ponterotto, J. M. Cass, L.A. Suzuki, and C.M. Alexanders (Eds.), Handbook of multicultural counselling (pp 73-92). Thousand Oaks, CA:Sage.

Comley, P. (1996), "The Use of the Internet as a Data Collection Method," SGA MarketResearch, [Online] Available: http://www.sga.co.uk/esomar.html

Daily, B. (1988). The roots of the problems in Native communities. In T. Martens, B. Daily, M. Hodgson \& the Nechi Institute (Eds.), The spirit weeps: Characteristics and dynamics of incest and child sexual abuse (p. 107-122). Edmonton, AL: Nechi Institute. 
Diller, J. V. (1999). Cultural diversity: A primer for the human services. Belmont, CA: Wadsworth Publishing Company.

Driver, Harold E. (1956). An Integration of Functional, Evolutionary and Historical Theory by Means of Correlations. Indiana University Publications in Anthropological Linguistics, Memoir 12.

Ember, Carol R. (1988). Guide to Cross-cultural Research Using the HRAF. New Haven: HRAF Press.

Ember, Carol R. (1990). Bibliography of Cross-Cultural Research Methods. Cross-Cultural Research, Vol. 24, No. 1-4, 141-154 DOI: $10.1177 / 106939719002400107$

Ember, Carol R. (1992). With the assistance of Hugh Page, Jr., Timothy O'Leary, and M. Marlene Martin. Computerized Concordance of Cross-Cultural Samples. New Haven: Human Relations Area Files.

Ember, Carol R., and Melvin Ember. (1998). Cross-Cultural Research. In Handbook of Methodology in Cultural Anthropology, ed. H. Russell Bernard, 647-687. Walnut Creek, CA: Altamira Press

Harris, Marvin. (1968). The Rise of Anthropological Theory: A History of Theories of Culture. New York: Crowell.

Hart, S. (1995). Action in reflection. Educational Action Research, 3, 211-232.

Herring, R. (1999). Counselling Native American Indians and Alaska Natives. Thousand Oaks, CA: Sage.

Ho, D. R. (1994). Asian American perspective. In J. U. Gordon (Ed), Managing multiculturalism in substance abuse services (pp. 72-98). Thousand Oaks, CA: Sage.

Honadle, B. W. (1996). Participatory research for public issues education. Journal of the Community Development Society, 27, 56-77.

Hudson, P., \& Taylor-Henley, S. (2001). Beyond the rhetoric: Implementing culturally appropriate research projects in First Nations communities. American Indian Culture and Research Journal, 25, 93-105.

Koss-Chioino, J. D., \& Vargas, L. A. (1992). Through the cultural lookingglass: A model for understanding culturally responsive psychotherapies. In L. A. Vargas \& J. D. Koss-Chioino (Eds.), Working with culture: Psychotherapeutic interventions with ethnic minority children and adolescents (pp. 1-22). San Francisco, CA: Jossey-Bass.

LaFromboise, T.D. (1993). American Indian mental health policy. In D. R. Atkinson, G. Morten, \& D. W. Sue (Eds.), Counselling American minorities:A cross-cultural perspective. (4th ed.). (p. 123-144). Madison, WI: Brown \& Benchmark

Lagacé, Robert O. (1979). The HRAF Probability Sample: Retrospect and Prospect. Behavior Science Research 14: 211-229

Lee, C. C. (Ed.). (1995). Counselling for diversity. Needham Heights, MA: Allyn and Bacon.

Levinson, David and Melvin Ember, editors. (1996). Comparative Method. In Encyclopedia of Cultural Anthropology. 1: New York: Henry Holt.

Malone, J. L. (2000). Working with Aboriginal Women: Applying Feminis Therapy in a Multicultural Counselling Context. Canadian Journal of Counselling, 34, 33-42.

Martin, W. E., \& Farris, K. K. (1994). A cultural and contextual decision path to career assessment with Native Americans: A psychological perspective. Journal of Career Assessment, 2, 258-275.

Murdock, George P. (1967). Ethnographic Atlas. University of Pittsburgh Press. Also Ethnology 6:109-236.

Murdock, George P. (1981). Atlas of World Cultures. Pittsburgh: University of Pittsburgh Press.

Murdock, George Peter, and Douglas R. White. (1969). Standard Cross-Cultural Sample. Ethnology 9: 329-369. [Online] Available: http://repositories.cdlib.org/imbs/socdyn/wp/Standard_Cross-Cultural_Sample

Murdock, George Peter. (1968). World Sampling Provinces. Ethnology, 7: 305-326.

Murdock, George Peter. (1980). Theories of Illness: A World Survey. Pittsburgh, PA: University of Pittsburgh Press.

Naroll, Raoul. (1961). Two Solutions to Galton's Problem. In Readings in Cross-Cultural Methodology, edited by Frank Moore, pp.221-245. New Haven: HRAF Press.

Naroll, Raoul. (1967). The Proposed HRAF Probability Sample. Behavior Science Notes, 2: 70-80.

Parlee, M. B. (1983). President's letter. Division 35 (APA) Newsletter, 1-10.

Peavy, V. (1998). Socio-dynamic counselling: A constructivist perspective. Victoria: Trafford Publishing.

Pedersen, P. B. (1991). Multiculturalism as a generic approach to counselling. Journal of Counselling and Development, $70,6-12$. 
Piquemal, N. (2001). Free and Informed Consent in Research Involving Native American Communities. American Indian Culture and Research Journal, 25, 65-79.

Ponterotto, J. G., \& Casas J. M. (1993). Handbook of ethnic/racial minority counseling research. Springfield, IL: Charles C. Thomas.

Seymour-Smith, Charlotte. (1968). Macmillan Dictionary of Anthropology. London: Macmillan.

Smee, A. Brennan, M. Hoek, J. And Macpherson, T. (1998). "A Test of Procedures for Collecting Survey Data Using Electronic Mail," Refereed WIP paper, Australian and NewZealand Marketing Academy (ANZMAC) Conference Proceedings, 30 Nov - 2 December, University of Otago, Dunedin, New Zealand, pp.2447-2452.

Smith, D. B., \& Morrissette, P. J. (2001). The experiences of white male counselors who work with Aboriginals clients. Canadian Journal of Counselling, 35, 74-88.

Sommer, R. (1999). Action research: From mental hospital reform in Saskatchewan to community building in California. Canadian Psychology, 40, 47-55.

Stubben, J. (2001). Working with and conduction research among American Indian Families. American Behavioural Scientist, 44, 1466-1480.

Sue, D.W. \& Sue, D. (1990). Counselling the Culturally Different. New York: John Wiley \& Sons.

Thomason, T.C. (1999). Psychological and vocational assessment of Native Americans. ERIC Document ED432428. Greensboro, NC: ERIC Clearinghouse on Counseling and Student Services.

Tylor, Edward Burnett. (1889). On a Method of Investigating the Development of Institutions; Applies to Laws of Marriage and Descent. Journal of the Anthropological Institute, 18:245-272.

Weenie, A. (2000). Post colonial recovering and healing. In Learn in beauty: Indigenous education in a new century. [Online] Available: http://jan.ucc.nau.edu/-jar/LIB/LIB6. html

Weible, R. and Wallace, J. (1998). Cyber Research: The Impact of the Internet on Data Collection. Market Research, Fall, 10(3), pp.19-2.

Westwood, M. J., \& Ishiyama, F. (1990). The communication process as a critical intervention for client change in cross-cultural counselling. Journal of Multicultural Counseling and Development, 18, 163-171.

Wetsit, D. (1999). Effective counseling with American Indian students. In Next steps: Research and practice to advance Indian education. Information Analysis. Monterey, CA: Brooks/Cole.

Whiting, John W. M. (1954). "The Cross-Cultural Method." In Handbook of Social Psychology, Vol. 1. Gardner Lindzey, ed. Cambridge, Mass.: Addison-Wesley, pp. 523-31. Reprinted in Readings in Cross-Cultural Methodology. Frank W. Moore, ed. New Haven: HRAF Press, pp. 287-300.

Whyte, W. F. (Ed.). (1991). Participatory action research. Newbury Park, CA: Sage.

Winthrop, Robert H. (1991). Dictionary of Concepts in Cultural Anthropology. New York: Greenwood Press.

\section{Notes}

Note 1. In Melvin Ember - 2001 Cross-cultural research methods - Google Books Result by - Social Science - 164 pages books.google.com/books?isbn=0742504271...

Note 2. In Melvin Ember - 2001 Cross-cultural research methods - Google Books Result by - Social Science - 164 pages books.google.com/books?isbn=0742504271...

Note 3. http://www.as.ua.edu/ant/Faculty/murphy/crosscut.htm.

Note 4. In Melvin Ember - 2001 Cross-cultural research methods - Google Books Result by - Social Science - 164 pages books.google.com/books?isbn=0742504271...

Note 5. http://www.as.ua.edu/ant/Faculty/murphy/crosscut.htm.

Note 6. In Melvin Ember - 2001 Cross-cultural research methods - Google Books Result by - Social Science - 164 pages books.google.com/books?isbn=0742504271...

Note 7. http://www.as.ua.edu/ant/Faculty/murphy/crosscut.htm.

Note 8. In Melvin Ember - 2001 Cross-cultural research methods - Google Books Result by - Social Science - 164 pages books.google.com/books?isbn=0742504271...

Note 9. In Melvin Ember - 2001 Cross-cultural research methods - Google Books Result by - Social Science - 164 pages books.google.com/books?isbn=0742504271.. 